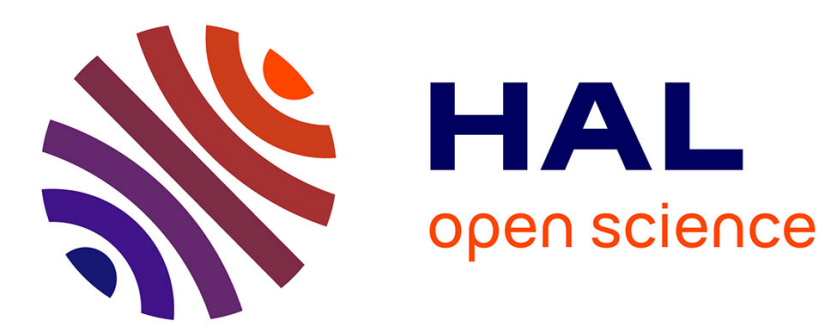

\title{
Peptide nucleic acid-nanodiamonds: covalent and stable conjugates for DNA targeting
}

Claire Gaillard, Hugues Girard, Caroline Falck, Vincent Paget, Vesna Simic, Nicolas Ugolin, Philippe Bergonzo, Sylvie Chevillard, Jean-Charles Arnault

\section{- To cite this version:}

Claire Gaillard, Hugues Girard, Caroline Falck, Vincent Paget, Vesna Simic, et al.. Peptide nucleic acid-nanodiamonds: covalent and stable conjugates for DNA targeting. RSC Advances, 2014, 4 (7), pp.3566 - 3572. 10.1039/c3ra45158e . cea-01832084

\section{HAL Id: cea-01832084 https://hal-cea.archives-ouvertes.fr/cea-01832084}

Submitted on 19 Jul 2019

HAL is a multi-disciplinary open access archive for the deposit and dissemination of scientific research documents, whether they are published or not. The documents may come from teaching and research institutions in France or abroad, or from public or private research centers.
L'archive ouverte pluridisciplinaire HAL, est destinée au dépôt et à la diffusion de documents scientifiques de niveau recherche, publiés ou non, émanant des établissements d'enseignement et de recherche français ou étrangers, des laboratoires publics ou privés. 
Cite this: RSC Adv., 2014, 4, 3566

\title{
Peptide nucleic acid-nanodiamonds: covalent and stable conjugates for DNA targeting $\dagger$
}

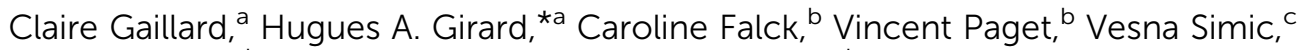 \\ Nicolas Ugolin, ${ }^{\mathrm{b}}$ Philippe Bergonzo, ${ }^{a}$ Sylvie Chevillard ${ }^{\mathrm{b}}$ and Jean Charles Arnault ${ }^{\mathrm{a}}$
}

This article highlights our recent application of functional nanodiamonds (NDs) with peptide nucleic acids (PNA) to develop tools for DNA detection. NDs appear as an ideal nanocarrier due to their versatile surface chemistry, their non-cytotoxicity and since they could benefit from intrinsic luminescent properties. In this work, we report for the first time the possibility to prepare a covalent, stable and functional conjugate of PNA with $20 \mathrm{~nm}$ HPHT (High Pressure High Temperature) nanodiamonds. Peptide nucleic acid is a DNA mimic related to both peptides via its backbone and to nucleic acid via its bases. It binds more specifically and more strongly than DNA itself to either DNA or RNA. We have initiated a novel functionalization route based on an optimized amidation of ND carboxylic acid groups, to produce NDPNA conjugates via an efficient, simple and reproducible method. We describe the synthesis and characterization of those conjugates. The covalent binding of the ND-PNA and the loading of nucleic acid grafted onto the NDs were performed using various characterization methods including FTIR, Kaiser tests and thermogravimetry. Then, ND-PNA conjugates were validated through a successful recognition of complementary DNA in a mixture, showing their efficiency toward nucleic acid detection. Moreover, the impact of ND-PNA on A 549 cells' viability was analysed with flow cytometry and showed an absence of ND-PNA conjugates cytotoxicity. Such nucleic acid-functionalized nanodiamonds offer a wide range of applications and namely the possibility to target and to recognize DNA.

Received 16th September 2013 Accepted 17th October 2013

DOI: 10.1039/c3ra45158e

www.rsc.org/advances

\section{A Introduction}

In recent years, nucleic acid-nanoparticle conjugates have received considerable scientific interest because of their biomedical and bioengineering applications. Such conjugates have been the subject of extensive studies toward gene delivery and bioassays because selective and sensitive detection is essential for tracking genetic disease, genomic research or early diagnosis for cancer. ${ }^{1,2}$ In that sense, DNA functionalization has already been reviewed and widely detailed for several nanoparticles such as carbon nanotubes (CNTs), ${ }^{3-5}$ metal nanoparticles $^{6-8}$ polymeric nanobeads, ${ }^{9,10}$ or silica nanoparticles. ${ }^{11}$

Among the nucleic acids available for such applications, recent works reported on synthetic peptidic nucleic acids (PNA) demonstrated enhanced stability with respect to DNA. ${ }^{12}$ Indeed, PNA is related to both peptides via its rigid backbone and

${ }^{a}$ CEA, LIST, Diamond Sensors Laboratory, F-91191 Gif-sur-Yvette, France. E-mail: hugues.girard@cea.fr; Tel: +33 169084760

${ }^{b}$ CEA, iRCM, Laboratory of Experimental Cancerology, F-92265 Fontenay-aux-Roses, France

${ }^{c}$ CEA, LIST, Sensors and Electronic Architectures Laboratory, F-91191 Gif-sur-Yvette, France

$\dagger$ Electronic supplementary information (ESI) available: Materials and method and details about cytotoxicity study of A549 cells exposed $24 \mathrm{~h}$ to ND-PNA. See DOI: $10.1039 / \mathrm{c} 3 \mathrm{ra} 45158 \mathrm{e}$ nucleic acid via its bases. ${ }^{13,14}$ It can be hybridized to complementary DNA and RNA sequences because of comparable intermolecular distances configurations. The uncharged peptide backbone represents an advantage towards the hybridization of nucleic acids since it avoids the effect of electrostatic repulsion between PNA with negatively charged DNA and RNA. The PNA binding is thus more selective and stronger than DNA itself to either DNA or RNA, with a better chemical and thermal stability, as PNA are neither degraded by nucleases nor proteases. Indeed, it is well known that small PNA strands (between 10 and 18 bases) are usually used to target in vivo or in vitro by hybridization different sequences of DNA like telomers, gene sequences, or RNA like mRNA or ribosomal RNA. ${ }^{14}$ Surprisingly, nanoparticles-PNA (NP-PNA) conjugates have been very poorly investigated so far when compared with NP-DNA conjugates, and recent publications mostly focus on NP-PNA conjugates for detection. For instance, CNT-PNA were used as nanoelectrode platforms and metallic NP-PNA as substrates for colorimetric detection toward efficient DNA recognition in biosensors. ${ }^{15,16}$ PNA functionalization of quantum dots (QDs) was also described for long-term intracellular and intranuclear tracking studies. ${ }^{17}$ Nevertheless, toward gene detection, the specificity and stability of NP-PNA conjugates would also be of great interest. In such a case, an ideal nanocarrier would have to allow a stable PNA binding onto a 
nontoxic, low cost and available nanomaterial, further to exhibiting fluorescent properties for labelling capacities.

In this context, nanodiamonds (NDs) thus represent an interesting and stable chemical platform to extract oligonucleotides. Indeed, NDs have attracted growing interest in recent years, as their carbon-related surface chemistry provides an efficient and versatile platform for bio-conjugation toward therapeutic applications, ${ }^{18-22}$ whilst their diamond cores host an embedded luminescent $\mathrm{N}-\mathrm{V}$ center, ${ }^{23}$ perfectly photostable and well adapted for bio-labelling in organisms and cell cultures. ${ }^{24}$ Their production and purification are now well established, either from the detonation technique, from laser ablation or via milling of HPHT (High Pressure High Temperature) diamonds. ${ }^{10}$ ND with sizes ranging from nanometers to a few tens of nanometers could be produced in large quantity at low cost. ${ }^{25}$ Furthermore, several long-term in vitro $^{23,24}$ as well as in vivo ${ }^{26-28}$ studies have demonstrated that NDs are non-cytotoxic and show an enhanced cell tolerance compared to other nanocarbon materials. ${ }^{21}$ From subsequent surface treatments to homogenize their surface chemistry, ${ }^{12,13,30-32}$ it has been made possible to conjugate ND surfaces with fluorescent molecules, ${ }^{26-29}$ with DNA, ${ }^{33}$ siRNA, ${ }^{22}$ proteins, ${ }^{34,35,36}$ lysozymes,${ }^{35}$ growth hormones, ${ }^{37}$ antibodies, ${ }^{38,39}$ and anti-cancer drugs, ${ }^{40-42}$ as well as with dopamine derivatives. ${ }^{\mathbf{4 3}}$

ND-oligonucleotide conjugates already reported in the literature were mostly designed toward gene therapy, then based onto electrostatic interactions to allow a delivery. ${ }^{22,33}$ Here we report on covalent ND-PNA conjugate synthesis, stable and functional, realized through an efficient, simple and reproducible method. We focused our approach on the possibility of covalently binding PNA directly on the carbon atoms of the diamond core. Taking advantage of the carbon-related chemistry of NDs, we aim at increasing the conjugate stability, accessibility, and selectivity during competitive hybridizations. PNA (polythymine) functionalization has thus been achieved through an optimized amidation of carboxylic acid groups present at the ND surface. Synthesis and characterization of those conjugates will be described and the covalent binding of the ND-PNA is evidenced from infrared spectroscopy (FTIR) as well as from Kaiser tests. The quantification of nucleic acids grafted onto NDs is then performed using thermogravimetric (TGA) and spectrofluorimetry analyses. We show that PNA molecules covalently linked to NDs are accessible for subsequent hybridization through the successful matching with complementary DNA present in a mixture, thus demonstrating their efficiency for molecular diagnosis. Finally, the cytotoxicity of ND-PNA was studied and no cell mortality was recorded even for ND-PNA highest dose. These studies demonstrate the ability of those conjugates to be used in advanced biomedical devices and their potential applications in biomedicine.

\section{B Results and discussion}

\section{Synthesis of nanodiamonds functionalized with peptide nucleic acid}

Acidic treatments or annealing in air are common methods enabling the covering of NDs with a high density of carboxylic groups on their surface, ${ }^{19}$ allowing an enhanced colloidal stability to NDs suspensions. Typically, loading values from 0.1 to $0.8 \mathrm{COOH}$ per $\mathrm{nm}^{2}$ depending on NDs synthesis have been reported. ${ }^{\mathbf{4 3 , 4 4}}$ Commercial NDs are thus often provided with such a surface chemistry, as is the case for the NDs used in the present study. ${ }^{30}$ Note that the presence of such carboxylic groups on our NDs is confirmed by zetametry which evidenced a negatively charged surface above $\mathrm{pH}=5$ (Fig. 1).

To create a covalent binding between PNA and NDs, a coupling strategy can thus rely on the creation of an amide between these carboxylic groups and PNA terminal amino groups. Regarding the literature, different strategies could be chosen for such amidation. Focusing on NDs, many studies report approaches via the chlorure thionyl procedure, ${ }^{\mathbf{1 0 , 4 5}}$ although it requires drastic conditions (excess, reflux and time). As an alternative, the carbodiimide-activated coupling is known to be particularly suitable for the functionalization of carbon nanomaterials with biomolecules and biological species. ${ }^{46}$ This way was preferred here to conjugate PNA to NDs using peptide coupling reagents and namely 1-ethyl-3-(3-dimethylaminopropyl)carbodiimide and hydrochloride- $N$-hydroxysuccinimide (EDC-NHS).

Several parameters were optimized that include solvent nature (dimethylformamide, dioxane, water), temperature and precursor order during the reaction to finally converge towards a protocol where functionalization was achieved at room temperature in dimethylformamide (DMF) (Scheme 1) enabling an enhanced dispersion of NDs when compared to other solvents. Carboxylic groups at the ND surface were first activated with EDC-NHS coupling and after elimination of this compound, PNA were added in presence of $N, N$-diisopropylethylamine (DIEA) (see Experimental section and ESI $\dagger$ ).

Functionalized NDs with polyT PNA were first characterized using dynamic light scattering (DLS) (Fig. 1). From an initial mean value of $24 \mathrm{~nm}$, their diameter only slightly increases up to $44 \mathrm{~nm}$ after several washings and their redispersion in pure water. This good dispersion is presumably ensured by the preservation of a high surface charge after functionalization, with a zeta potential $\zeta$ equal to $-38 \mathrm{mV}$. This negative charge may either originate from the NDs carboxylic groups unsaturated with amide bonds, or PNA carboxylic groups.

The grafting of NDs was then investigated using Fourier transform infrared (FTIR) spectroscopy. To overcome peaks related to adsorbed water on the spectrum (typ. at $1640 \mathrm{~cm}^{-1}$ and 3300-3400 $\mathrm{cm}^{-1}$ ), samples were dried in situ at $50^{\circ} \mathrm{C}$ under vacuum for 24 hours before measurement using a specifically designed IR reactor cell. Fig. 2 shows the spectra of free

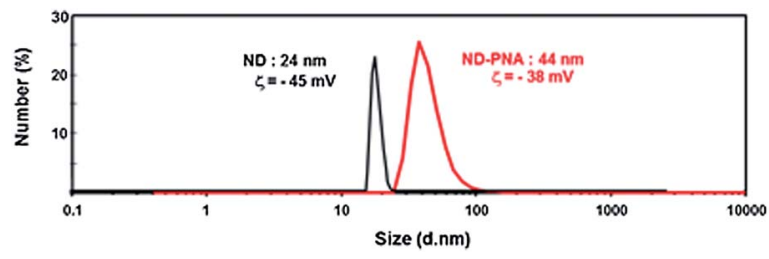

Fig. 1 Size measurement as estimated from dynamic light scattering and zeta measurements $(\zeta)$ of ND and ND-PNA suspended in water $(\mathrm{pH}=5)$ 


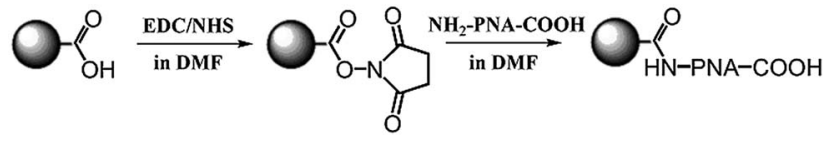

Scheme 1 Synthesis of ND-peptide nucleic acid polyT conjugates.

polythymine PNA (blue curve), as received NDs (purple curve) and ND-PNA (red curve). The NDs mainly exhibit a strong band around $1780 \mathrm{~cm}^{-1}$ relating to carboxylic groups ${ }^{30}$ and show a weak contribution of $\mathrm{C}-\mathrm{H}$ stretching modes between 2920 and $3000 \mathrm{~cm}^{-1}$. $^{30}$ After coupling with PNA, the ND-PNA spectrum exhibits a strong signal at $1630 \mathrm{~cm}^{-1}$ which corresponds to the $\mathrm{C}=\mathrm{O}$ stretching of amide functions, also clearly present in the PNA spectrum. In parallel, NH deformation band at $1545 \mathrm{~cm}^{-1}$ could also be observed on the PNA spectrum and as a shoulder shape in the ND-PNA signal. These bands at 1545 and 1630 $\mathrm{cm}^{-1}$ are clear PNA signatures present on the NDs surfaces.

If FTIR evidences the presence of PNA onto ND, this technique is unable to confirm the formation of the amide bond between both conjugates, hidden on the spectra by the amide bonds already present on the PNA backbone. To gain further insights into the chemistry of ND-PNA, a colorimetric assay (the so called Kaiser test) frequently used in peptide chemistry ${ }^{47}$ was assessed to check the disappearance of free amino groups. Indeed, terminal amino groups on PNA should have been turned into amide bonds in case of successful coupling. Fig. 3 compares Kaiser tests performed on ND-PNA conjugates with those done onto two control solutions. The positive control (blue coloured) achieved with ethylene diamine functionalized NDs evidences the sensitivity of the Kaiser method to free amino groups grafted onto NDs. On a stable suspension of NDPNA, no presence of free primary amines groups is revealed during the Kaiser test, thus confirming their disappearance in favour to amide bonds. Considering the FTIR analysis and these colorimetric assays, an effective covalent binding between PNA and NDs is thus strongly supported.

To quantify the PNA conjugation to NDs, thermogravimetric analysis (TGA) was performed (Fig. 4A and B). On the differential thermogravimetric (DTG) curves of NDs (Fig. 4A) and NDPNA (Fig. 4B), 3 different thresholds could be observed. The first weight loss below $200{ }^{\circ} \mathrm{C}$ is due to adsorbed species including

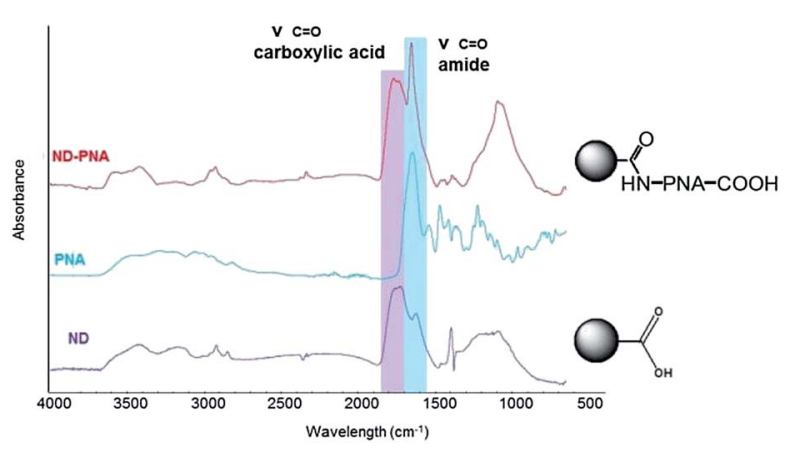

Fig. 2 FTIR spectra of as received ND (purple curve), PNA (blue curve) and ND-PNA (red curve).

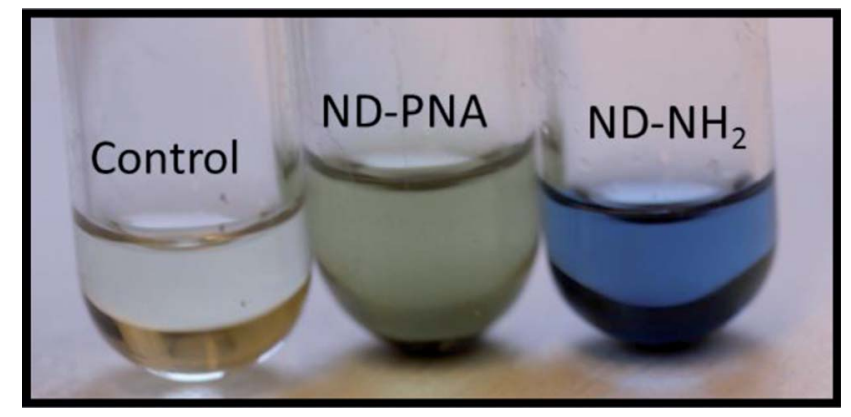

Fig. 3 Colorimetric assay (Kaiser test) of ND-PNA, and ND-NH $\mathrm{N}_{2}$ as the positive control. The blue colour indicates the presence of free amino groups.

water. ${ }^{48}$ Removal of the surface functional groups only starts beyond $300{ }^{\circ} \mathrm{C}$ and corresponds to the second weight loss. ${ }^{49}$ Similar observations favouring covalent functionalization at this temperature were reported in the literature. ${ }^{48-50}$ The third threshold is attributed to the ND pyrolysis. ${ }^{50}$ Comparing ND and ND-PNA TGA curves in the second weight loss range, a difference of $c a$. $2.5 \mathrm{wt} \%$ associated with covalently bonded molecules can be determined before and after functionalization (Fig. 4C). If we attribute this difference to PNA removal, the loading of PNA onto NDs is thus $10 \mathrm{nmol} \mathrm{mg}^{-1}$, which corresponds to a value of 90 PNA molecules for one ND if the particle is considered as a $20 \mathrm{~nm}$ diameter sphere. This high loading of PNA by nanoparticles should thus ensure a high hybridization probability between PNA and DNA.

\section{Hybridization of peptide nucleic acid-functionalized nanodiamonds}

As PNA hybridization was shown to be more specific and stronger than DNA itself to either DNA or RNA, ${ }^{14}$ ND-PNA conjugates would have the benefit of the same properties. To guarantee the capacities of these ND-PNA conjugates towards DNA recognition, a hybridization test was performed using a specific DNA sequence. ND-PNA and NDs were dispersed in a solution containing complementary polyA DNA labelled with Cyanine 3 (Сy3) in a hybridization buffer. After several washing steps to remove the DNA excess, a drop on a slide was observed

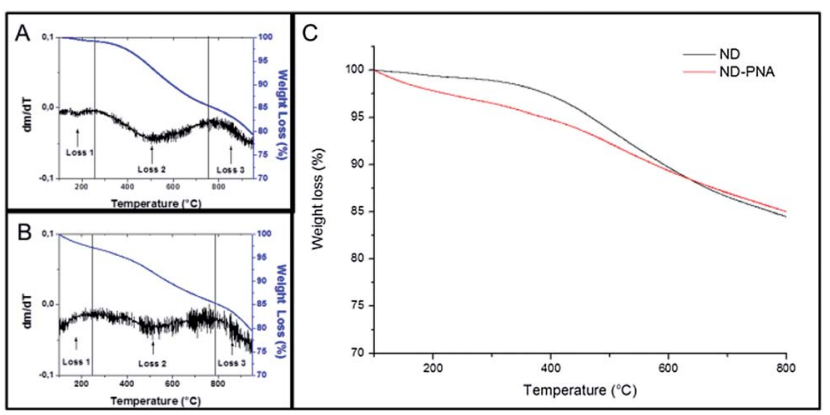

Fig. 4 Differential thermogravimetric (DTG) and TGA curve of ND (A), differential thermogravimetric (DTG) curve of ND-PNA (B), thermogravimetric analysis (TGA) of ND as received and ND-PNA (C). 
under fluorescent microscopy. Resulting pictures of NDs and ND-PNA conjugates are compared after the same treatment on Fig. 5, respectively. The fluorescence resulting from the Cy3labelled DNA clearly evidences the effective DNA recognition and hybridization with ND-PNA. On the contrary, only low fluorescence traces are observed when NDs were used for such hybridization tests, suggesting a very limited nonspecific interaction between DNA and non-functionalized NDs. A repulsion effect between DNA and the strong negative charge $(-45 \mathrm{mV})$ of the carboxylated NDs may explain these phenomenon, as already reported by Kong et $a l .{ }^{51}$ These observations provide a first qualitative comparison.

Hybridized DNA loaded onto ND-PNA was then studied using spectrofluorimetry in order to quantify DNA molecules after hybridization for 45 minutes. First, the fluorescence intensity of Cy3 was calibrated using three concentrations of DNA-Cy3 (Fig. 6). After hybridization and several washes, the fluorescence intensities of NDs and ND-PNA were recorded. Note that the background fluorescence coming from non-functionalized NDs was estimated prior to the experiments and subtracted from all measurements. Table 1 reports the fluorescence intensity of DNA-Cy3 after their hybridization onto ND-PNA at several concentrations ranging from 0.025 to $0.01 \mathrm{mg} \mathrm{mL} \mathrm{m}^{-1}$. The concentration of DNA-Cy3 was deduced using the calibration curve (Fig. 6). Taking into account the ND concentration, the DNA-Cy3 loading onto ND-PNA was estimated to be 0.8 to 1.1 nanomoles per $\mathrm{mg}$ of ND. Assuming NDs are $20 \mathrm{~nm}$ spheres, an average number of 8 DNA molecules are hybridized per ND-PNA conjugate. If this value is sufficient to use these stable nanohybrids for oligonucleotide detection, it has to be compared to the 90 PNA moieties previously shown to be grafted onto one ND. Here, the hybridization of DNA molecules is probably limited by a steric effect of PNA grafted on the NDs as well as by electrostatic effects due to the repulsive interaction between DNA-DNA and DNA-negatively charged ND-PNA.

ND-PNA conjugates were proven here to efficiently recognize DNA and thus constitute promising tools for diagnostics

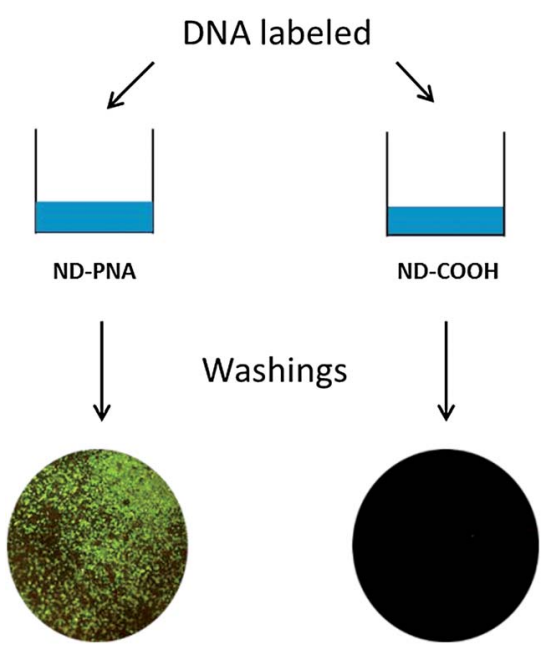

Fig. 5 Fluorescent microscopy pictures of nanodiamonds deposited on a microscopic slide after DNA hybridization observed at $\lambda_{\text {exc }}=550$ $\mathrm{nm}$ and $\lambda_{\mathrm{em}}=570 \mathrm{~nm}$.

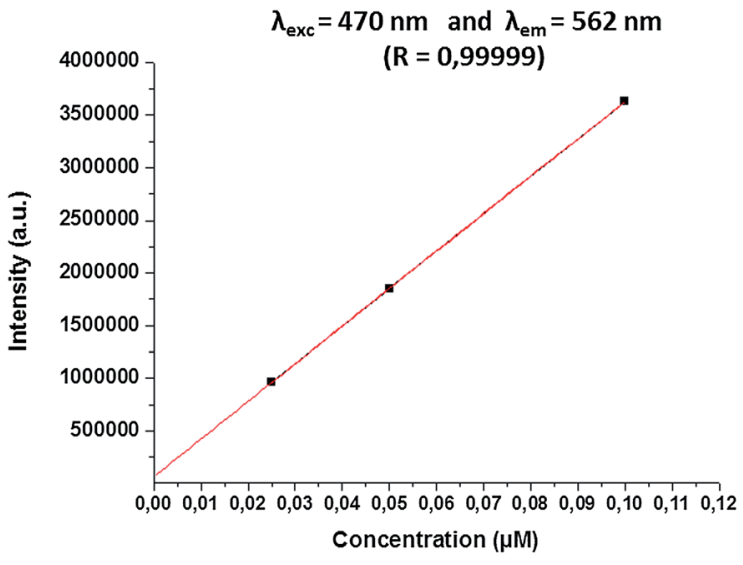

Fig. 6 Plot of the fluorescence intensity of Cy3-labelled DNA as a function of its concentration in a buffer solution $\left(\lambda_{\text {exc }}=470 \mathrm{~nm}\right.$ and $\left.\lambda_{\mathrm{em}}=562 \mathrm{~nm}\right)$. A linear fit to the data points gives: $I=3.5 \times 10^{7} \mathrm{C}+$ 73362 where $C$ is the concentration of labelled DNA $(\mu M)$ and / the fluorescence intensity.

applications. To integrate these conjugates into advanced biomedical devices, we started to explore their ability for specific DNA recognition.

Specific DNA recognition of peptide nucleic acidfunctionalized nanodiamond

Our ND-PNA conjugates were aimed at the possibility to specifically target a given DNA molecule present in a mixture of DNA molecules as in biologic samples. PNA is known to bind very specifically as only a single base pairing mismatch in PNADNA complexes is less stable than in DNA-DNA duplexes. ${ }^{\mathbf{1 4}}$ However, in a biological sample, NDs could adsorb other compounds such as non-complementary DNA. In order to check their specificity and efficiency, ND-PNA was dispersed in a hybridization buffer with a mixture of labelled-DNA. The complementary polyA DNA sequence was labelled with Cy3 while fluorescein-polyT was used for the non-complementary DNA. As a negative control, NDs were also dispersed in an equivalent mixture of labelled-DNA. After one hour, the suspensions were washed to eliminate excessive DNA and observed under fluorescent microscopy with two distinct filters to detect selectively the two different labels (Fig. 7).

The hybridization between complementary DNA and NDPNA is clearly observed (Fig. 7A), contrary to as received NDs where only very low fluorescence traces were observed (Fig. 7B). Concerning the non-complementary DNA, no fluorescence signal is detected, proving that they were not recognized neither by ND-PNA (Fig. 7C) nor by non-functionalized NDs (Fig. 7D). This simple test thus confirms the specificity of ND-PNA and the potential efficiency of these nanodiamond-based nanotools.

\section{In vitro tests of peptide nucleic acid-functionalized nanodiamonds}

As we aim to use ND-PNA in advanced biomedical devices, in vitro tests were then performed with these conjugates. The impact of ND-PNA on cell viability was analyzed by measuring 
Table 1 Calculations of DNA molecules hybridized on NDs deduced by spectrofluorimetry

\begin{tabular}{lllll}
\hline $\begin{array}{l}\text { ND concentration } \\
\left(\mathrm{mg} \mathrm{mL}^{-1}\right)\end{array}$ & $\begin{array}{l}\text { Fluorescence intensity } \\
\text { of ND-PNA }\end{array}$ & $\begin{array}{l}\text { Fluorescence } \\
\text { intensity of NDs }\end{array}$ & $\begin{array}{l}\text { DNA labelled concentration } \\
\left(\mathrm{nmol} \mathrm{g}^{-1}\right)\end{array}$ & DNA molecules per ND \\
\hline 0.025 & $1.04775 \times 10^{6}$ & 303320 & 0.8 & 7 \\
0.0125 & $6.68806 \times 10^{5}$ & 234530 & 0.8 & 7 \\
0.01 & $6.94826 \times 10^{5}$ & 210145 & 1.1 & 9
\end{tabular}
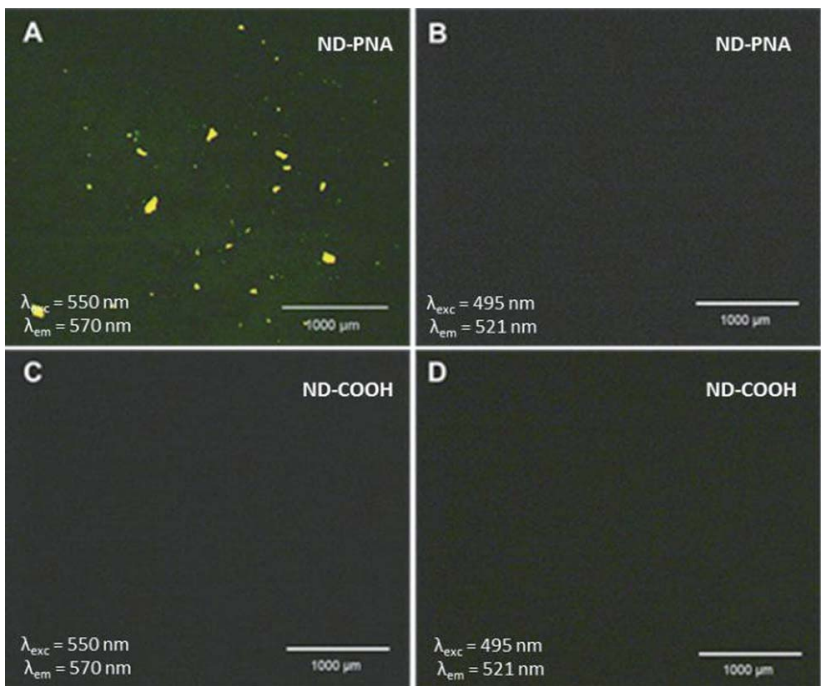

Fig. 7 Fluorescent microscopy pictures of as received NDs (pictures $C$ and D) and ND-PNA (pictures A and B) deposited on a microscopic slide after DNA hybridization observed at $\lambda_{\mathrm{exc}}=550 \mathrm{~nm}$ and $\lambda_{\mathrm{em}}=570$ $\mathrm{nm}$ for pictures (A) and (B) and at $\lambda_{\mathrm{exc}}=495 \mathrm{~nm}$ and $\lambda_{\mathrm{em}}=521 \mathrm{~nm}$ for pictures (C) and (D).

To-Pro-3 DNA staining by flow cytometry. ${ }^{52}$ Furthermore, by measuring light scattering deviation (SSC deviation) as described by Zucker et al. ${ }^{53,54}$ for $\mathrm{TiO}_{2}$ nanoparticles, flow cytometry was also used to estimate cell viability and if nanoparticles either interacted with the cell membrane or entered the cells. For the A549 cell line treated with ND-PNA at concentrations from 1 to $150 \mu \mathrm{g} \mathrm{mL} \mathrm{m}^{-1}$ over $24 \mathrm{~h}$, living cells with nanoparticles, living cells without nanoparticles and dead cells are reported in the ESI S2. $\dagger$ Cell mortality was estimated by means of the To-Pro-3 signal recorded in the FL4 channel, while ND-cell interactions were detected by an increase in the SCC channel (ESI S2 a and $\mathrm{b} \dagger$ ). An example of a biparametric analysis of the interactions/mortality of A549 cells exposed to ND-PNA at concentrations of 10 and $50 \mu \mathrm{g} \mathrm{mL}{ }^{-1}$ is reported in ESI S2 a. $\dagger$ Moreover, the A549 cell line was exposed for $24 \mathrm{~h}$ to aminated polystyrene nanobeads ( $\mathrm{PS}-\mathrm{NH}_{2}$ ) used as a positive control, to demonstrate the high sensitivity of the techniques used, but also allows benchmarking of the absence of NDs' cytotoxicity (ESI S2c $\dagger$ ). Indeed PS- $\mathrm{NH}_{2}$ was recently identified as one of four materials with an acute toxicity profile ${ }^{55}$ including cytotoxicity and membrane damage ${ }^{56}$ and activation of the inflamasome pathway. ${ }^{57}$ As seen in ESI S2c $\dagger$ after $24 \mathrm{~h}$ exposure, a clear cytotoxic effect was observed for A549 treated with PS- $\mathrm{NH}_{2}$ nanobeads, while no cytotoxic effects were observed at the same

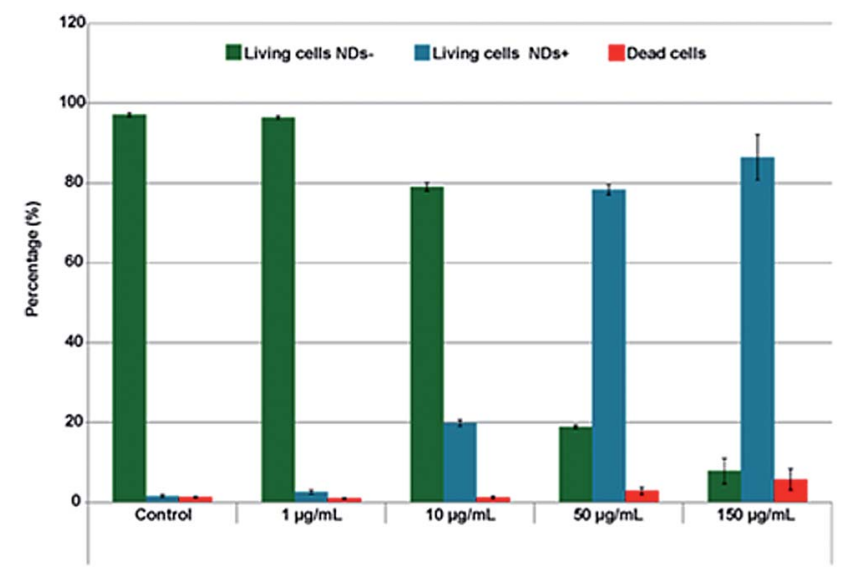

Fig. 8 Detection of ND-PNA and the associated mortality for A549 cells exposed $24 \mathrm{~h}$ to ND-PNA. Results are represented as the mean value of 3 independent experiments, the analysis of each experiment being performed on $2 \times 10^{4}$ events.

concentrations for A549 cells exposed to ND-PNA (ESI S2b $\dagger$ ). Overall the results confirm the absence of cell mortality even at the highest dose of $150 \mu \mathrm{g} \mathrm{mL} \mathrm{m}^{-1}$ ND-PNA where more than $80 \%$ of the cell population presents interactions with ND-PNA (Fig. 8).

In comparison, a $24 \mathrm{~h}$ exposure to $150 \mu \mathrm{g}$ per mL of PS- $\mathrm{NH}_{2}$ nanobeads leads to $99.8 \%$ of mortality of the A549 cells (ESI S2c $\dagger$ ).

The observed absence of cytotoxicity makes ND-PNA, and more generally HPHT NDs, ${ }^{58}$ ideal candidates for biomedical applications compared to other types of nanomaterials. These promising in vitro toxicity studies may be considered as preliminary results for the in vivo analysis for nanomedicine applications.

\section{Conclusion}

In this work, we successfully reported the possibility to functionalize $20 \mathrm{~nm}$ nanodiamonds with PNA. A simple method was developed to produce such covalent and functional ND-PNA conjugates through an optimized amidation of ND carboxylic acid groups using peptide coupling reagents. This is an original approach as the covalent stable functionalization of NDs with nucleic acid had not yet been explored. Indeed, the PNA covalent binding is essential to respect the vectorial sense of nucleic bases sequences, and to ensure a specific hybridization with corresponding DNA or RNA. This conjugation procedure is reproducible and requires no special modifications to 
commercial PNA sequences or even commercial NDs. PolyT PNA were grafted in this study onto NDs as a proof of concept, but the method is suitable for other PNA sequences carrying unprotected terminal amino groups (see ESI $\dagger$ ). Moreover, covalent binding enables the NDs to keep a negatively charged surface to limit nonspecific interactions between DNA and the NDs.

FTIR, Kaiser tests, spectrofluorimetry, and TGA analyses have demonstrated the effectiveness of the covalent binding of PNA onto the NDs as well as their successful availability for DNA hybridization. NDs appear as a well-adapted platform, widely available at low price (few $\$$ per $\mathrm{g}$ ), ${ }^{51}$ that combine the required properties and chemical stability of the diamond core. NDs also offer an easy to functionalize surface allowing covalent and stable binding, further to the subsequent possibility to host stable colored centers. DNA recognition facilities are conferred by the use of PNA instead of DNA, due to their ability to bind more specifically and strongly to DNA.

The absence of in vitro cytotoxicity and the ability of ND-PNA conjugates to selectively hybridize with DNA demonstrate their potential as promising nanotool candidates towards molecularbased diagnosis. Such nucleic acid-functionalized NDs may contribute to the development of new biomedical tools towards genetic diseases, genomic research or early cancer diagnosis.

\section{Acknowledgements}

The authors are grateful for financial support from the French Funding Agency (ANR), by the mean of the NanoCTC project (ANR-10-NANO-05-04) and wish to thank S. Campidelli from Molecular Electronic Laboratory at IRAMIS, CEA (France) for precious help on the TGA analysis.

\section{Notes and references}

1 J. Wang, Nucleic Acids Res., 2000, 28, 3011.

2 D. Murphya, G. Redmonda, B. G. Torreb and R. Eritja, Helv. Chim. Acta, 2004, 87, 2727.

3 R. R. Johnson, A. T. Charlie Johnson and M. L. Klein, Nano Lett., 2008, 8, 69.

4 R. Singh, D. Pantarotto, D. McCarthy, O. Chaloin, J. Hoebeke, C. D. Partidos, J. P. Briand, M. Prato, A. Bianco and K. Kostarelos, J. Am. Chem. Soc., 2005, 127, 4388.

5 M. Hazani, R. Naaman, F. Hennrich and M. M. Kappes, Nano Lett., 2003, 3, 153.

6 C. M. Niemeyer and U. Simon, Eur. J. Inorg. Chem., 2005, 18, 3641.

7 A. A. Lazarides and G. C. Schatz, J. Phys. Chem. B, 2000, 104, 460.

8 D. Graham, D. G. Thompson, W. Ewen Smith and K. Faulds, Nat. Nanotechnol., 2008, 3, 548.

9 P. W. Leea, S. F. Penga, C. J. Sua, F. L. Mib, H. L. Chena, M. C. Weia, H. J. Linc and H. W. Sunga, Biomaterials, 2008, 29, 742 .

10 S. Mansouri, P. Lavigne, K. Corsi, M. Benderdour, E. Beaumont and J. C. Fernandes, Eur. J. Pharm. Biopharm., 2004, 57, 1 .
11 X. Zhao, R. Tapec-Dytioco and W. Tan, J. Am. Chem. Soc., 2003, 125, 11474.

12 P. E. Nielsen, M. Egholm, R. H. Berg and O. Buchardt, Science, 1991, 254, 1497.

13 B. Hyrup and P. E. Nielsen, Bioorg. Med. Chem., 1996, 4, 5.

14 P. E. Nielsen, Sci. Med., 1998, 5, 48.

15 R. Kanjanawarut and X. Su, Anal. Chem., 2009, 81, 6122.

16 S. K. Kim, H. Cho, J. Jeong, J. N. Kwon, Y. Jungab and B. H. Chung, Chem. Commun., 2010, 46, 3315.

17 C. Srinivasan, J. Lee, F. Papadimitrakopoulos, L. K. Silbart, M. Zhao and D. J. Burgess, Mol. Ther., 2006, 14, 192.

18 V. N. Mochalin, O. Shenderova, D. Ho and Y. Gogotsi, Nat. Nanotechnol., 2012, 7, 11.

19 A. Krueger and D. Lang, Adv. Funct. Mater., 2012, 22, 890.

20 H. A. Girard, T. Petit, S. Perruchas, T. Gacoin, C. Gesset, J. C. Arnault and P. Bergonzo, Phys. Chem. Chem. Phys., 2011, 13, 11517.

21 H. Huang, E. Pierstorff, E. Osawa and D. Ho, Nano Lett., 2007, 7, 3305.

22 A. Alhaddad, M. P. Adam, J. Botsoa, G. Dantelle, S. Perruchas, T. Gacoin, C. Mansuy, S. Lavielle, C. Malvy, F. Treussart and J. R. Bertrand, Small, 2011, 7, 3087.

23 S. J. Yu, M. W. Kang, H. C. Chang, K. M. Chen and Y. C. Yu, J. Am. Chem. Soc., 2005, 127, 17604.

24 J. I. Chao, E. Perevedentseva, P. H. Chung, K. K. Liu, C. Y. Cheng, C. C. Chang and C. L. Cheng, Biophys. J., 2007, 3, 2199.

25 A. M. Schrand, S. A. Ciftan Hens and O. A. Shenderova, Crit. Rev. Solid State Mat. Sci., 2009, 34, 18.

26 A. M. Schrand, J. B. Lin, S. C. Hens and S. M. Hussain, Nanoscale, 2011, 3, 435.

27 I. P. Chang, K. C. Hwang and C. S. Chiang, J. Am. Chem. Soc., 2008, 130, 15476.

28 U. Maitra, A. Jain, S. J. George and C. N. Rao, Nanoscale, 2011, 3, 3192.

29 Q. Zhang, V. N. Mochalin, I. Neitzel, I. Y. Knoke, J. Han, C. A. Klug, J. G. Zhou, P. I. Lelkes and Y. Gogotsi, Biomaterials, 2011, 32, 87.

30 H. A. Girard, J. C. Arnault, S. Perruchas, S. Saada, T. Gacoin, J. P. Boilot and P. Bergonzo, Diamond Relat. Mater., 2010, 19, 1117.

31 J. C. Arnault, T. Petit, H. Girard, A. Chavanne, C. Gesset, M. Sennour and M. Chaigneau, Phys. Chem. Chem. Phys., 2011, 13, 11481.

32 T. Petit, J. C. Arnault, H. A. Girard, M. Sennour and P. Bergonzo, Phys. Rev. B: Condens. Matter Mater. Phys, 2011, 84, 233407.

33 X. Q. Zhang, M. Chen, R. Lam, X. Y. Xu, E. Osawa and D. Ho, ACS Nano, 2009, 3, 2609.

34 A. Hartl, E. Schmich, J. A. Garrido, J. Hernando, S. C. R. Catharino, S. Walter, P. Feulner, A. Kromka, D. Steinmüller and M. Stutzmann, Nat. Mater., 2004, 3, 736. 35 Y. K. Tzeng, O. Faklaris, B. M. Chang, Y. Kuo, J. H. Hsu and H. C. Chang, Angew. Chem., Int. Ed., 2011, 50, 2262.

36 H. D. Wang, C. H. Niu, Q. Yang and I. Badea, Nanotechnology, 2011, 22, 145703. 
37 C. Y. Cheng, E. Perevedentseva, J. S. Tu, P. H. Chung, C. L. Chenga, K. K. Liu, J. I. Chao, P. H. Chen and C. C. Chang, Appl. Phys. Lett., 2007, 90, 163903.

38 D. T. Tran, V. Vermeeren, L. Grieten, S. Wenmackers, P. Wagner, J. Pollet, K. P. Janssen, L. Michiels and J. Lammertyn, Biosens. Bioelectron., 2011, 26, 2987.

39 A. H. Smith, E. M. Robinson, X. Q. Zhang, E. K. Chow, Y. Lin, E. Osawa, J. Xi and D. Ho, Nanoscale, 2011, 3, 2844.

40 K. K. Liu, W. W. Zheng, C. C. Wang, Y. C. Chiu, C. L. Cheng, Y.S. Lo, C. Chen and J. I. Chao, Nanotechnology, 2010, 21, 315106.

41 E. K. Chow, X. Q. Zhang, M. Chen, R. Lam, E. Robinson, H. Huang, D. Schaffer, E. Osawa, A. Goga and D. Ho, Sci. Transl. Med., 2011, 3, 73.

42 J. Li, Y. Zhu, W. Li, X. Zhang, Y. Peng and Q. Huang, Biomaterials, 2010, 31, 8410.

43 A. Barras, J. Lyskawa, S. Szunerits, P. Woisel and R. Boukherroub, Langmuir, 2011, 27, 12451.

44 L. Schmidlin, V. Pichot, M. Comet, S. Josset, P. Rabu and D. Spitzer, Diamond Relat. Mater., 2012, 22, 113.

45 V. N. Mochalin and Y. Gogotsi, J. Am. Chem. Soc., 2009, 131, 4594.

46 W. Huang, S. Fernando, L. F. Allard and Y. P. Sun, Nano Lett., 2003, 3, 565.

47 E. Kaiser, R. L. Colescott, C. D. Bossinger and P. I. Cook, Anal. Biochem., 1970, 34, 595.

48 W. W. Zheng, Y. H. Hsieh, Y. C. Chiu, S. J. Cai, C. L. Cheng and C. Chen, J. Mater. Chem., 2009, 19, 8432.
49 Y. Liu, Z. Gu, J. L. Margrave and V. N. Khabashesku, Chem. Mater., 2004, 16, 3924.

50 Y. Liu, Chemistry of Novel Nanoscale Carbon Material: Nanodiamond and Carbon Nano-onions, PhD Thesis, Rice University, 2005.

51 X. Kong, L. C. L. Huang, S.-C. V. Liau, C.-C. Han and H.-C. Chang, Anal. Chem., 2005, 77, 4273.

52 C. A. Van Hooijdonk, C. P. Glade and P. E. Van Erp, Cytometry, 1994, 17, 185.

53 R. M. Zucker and K. M. Daniel, Methods Mol. Biol., 2012, 906, 497.

54 R. M. Zucker, E. J. Massaro, K. M. Sanders, L. L. Degn and W. K. Boyes, Cytometry, Part A, 2010, 77, 677.

55 X. Z. Wang, Y. Yang, R. F. Li, C. McGuinnes, J. Adamson, I. L. Megson and K. Donaldson, Nanotoxicology, 2013, DOI: 10.3109/17435390.2013.796534.

56 P. Ruenraroengsak, P. Novak, D. Berhanu, A. J. Thorley, E. Valsami-Jones, J. Gorelik, Y. E. Korchev and T. D. Tetley, Nanotoxicology, 2012, 6, 94.

57 O. Lunov, T. Syrovets, C. Loos, G. U. Nienhaus, V. Mailander, K. Landfester, M. Rouis and T. Simmet, ACS Nano, 2011, 5, 96482.

58 V. Paget, J. A. Sergent, R. Grall, S. Altmeyer-Morel, H. A. Girard, T. Petit, C. Gesset, M. Mermoux, P. Bergonzo, J. C. Arnault and S. Chevillard, Nanotoxicology, 2013, DOI: 10.3109/17435390.2013.855828. 